\title{
The married middle working class turned out to be the most financially fragile group when facing multidrug-resistant tuberculosis in China cities
}

Peize Zhang ( $\sim$ peizezhang@aliyun.com )

Shenzhen Third People's hospital https://orcid.org/0000-0002-4023-0228

\section{Guanghui Xu}

Tuberculosis Prevention and Care Clinic of Jiangmen, China

\section{Yanhua Song}

Chest Hospital of Peaking, China

Jie Tan

The Third People's Hospital of Shenzhen

\section{Tao Chen}

The Third People's Hospital of Shenzhen

\section{Guofang Deng}

The Third People's Hospital of Shenzhen

Research article

Keywords: MIDDLE WORKING CLASS, CHINA, TUBERCULOSIS

Posted Date: December 23rd, 2019

DOl: https://doi.org/10.21203/rs.2.19439/v1

License: (c) (1) This work is licensed under a Creative Commons Attribution 4.0 International License.

Read Full License 


\section{Abstract}

INTRODUCTION With the emergence of multi-drug resistant tuberculosis and the threat it poses to public health, and the consequential cost involved in its treatment, constant effort has been put on evaluating and improving patient care to avoid treatment interference due to impoverishment of the household.

OBJECTIVE The aim of this study was to analyze socioeconomic burdens and other difficulties MDR-TB patients in cities are facing to identify major obstacles and which group of patients are most affected.METHODS Face-to-face and phone-call interviews were conducted in early 2018 to follow up with patients newly diagnosed with MDR-TB in 2017 in three tuberculosis clinics in China. Demographic data and information on their medical care, insurance coverage, medical expenses were collected and analyzed.

RESULTS A total of 144 newly-diagnosed MDR-TB cases were reviewed during the study period, among them 38 lost follow-up and 29 patients refused to participate. Eventually, 77 patients with MDR-TB were included in this study. 61 of these patients were hospitalized after MDR-TB diagnosis with an average hospital stay of 14.45 days, of them 57 were sputum positive on diagnosis. Ratio of home-discharged patients failing community care and returned to work were $48 \%$ and $8 \%$ for married and single persons ( $p$ $=0.001)$. In terms of insurance coverage, proportion of patients went back to work were $23 \%$ with no insurance and/or NRCMS and 45\% with UEBMI / URBMI and commercial insurance. Significant difference was shown between these two insurance coverage groups $(\chi 2=5.059, p=0.033)$. Difficulties patients encountered were financial pressure (33\%), psychological stress (26\%), adverse drug reactions (23\%), repulsive reaction to injections (17\%). $48 \%$ of the patients spent over CNY2,000 (USD300) per month on TB treatment.

CONCLUSION The married "middle working class" were found to be the most vulnerable group being affected financially. They have the highest tendency to fail community care schedule despite treatment status. It is of utmost urgency to enhance the current medical policy to cater for this group and improve treatment adherence.

\section{Introduction}

Tuberculosis (TB) is a pressing public health problem affecting millions of people globally every year and China is one of the high caseload countries. Even worse, China is among the top burden countries of multidrug-resistant tuberculosis (MDR-TB)[1]. Provision of care and support for these patients and disease control has become more challenging and a top priority concern.

It has been proved long before that with infectious disease, poverty is a major obstacle to cure and impoverishment can lead to adverse effect to disease control[2]. The China government has introduced various measures to help combat poverty resulted from medical treatment. The three Government subsidized insurance programs were the result of a nation-wide health system reform[3-5]. The New Rural Co-operative Medical Care Scheme (NRCMS) targets at rural populations including farmers and the low- 
income groups. Cost of insurance is CNY30 (USD4.5) / year which is minimal to make it affordable for the rural poor[6, 7]. The Urban Employee Basic Medical Insurance (UEBMI) covers the general working class and one thing worth to note is it is of a mandatory nature. Premium is $8 \%$ of an employees' wage of which $6 \%$ is contributed by employers and it provides a generally higher medical coverage. The Urban Residents Basic Medical Insurance (URBMI) is a household-level-voluntary medical insurance for those not covered by UEBMI, including children, students and other non-working residents[4, 5]. Despite the enormous effort, shortfalls still existed in certain aspects such as protection coverage and effectiveness.

In this study we aim to investigate real life problems encountered by MDR-TB patients in three generally mid- to high-income cities, identify major difficulties and suggest ways to tackle them via public health policy enhancement. The goal is to achieve higher cure rates and lower transmission rates through improving the overall wellbeing of these patients.

\section{Methods}

\subsection{Study Population}

A total of 144 newly diagnosed MDR-TB patients were recruited from three tuberculosis clinics from 3 China cities in 2017 in this study. 67 cases were excluded as 38 of them lost follow-up and 29 patients refused to participate, leaving 77 patients in this study. Face-to-face and phone-call interviews were conducted by their TB clinicians in early 2018. (Figure 1)

\subsection{Questionnaire design}

The questionnaire was designed to focus on the following aspects: 1/ sociodemographic characteristics, $2 /$ medical condition and care received, 3 / difficulties encountered, 4 / family financial situation and insurance coverage, 5 / amount spent on medical expenses and 6/ adherence to suggested community care (home isolation) schedule.

Sociodemographic characteristics included age, gender, marital status, occupation and education level. Medical conditions were presented in the form of length of hospitalization, result of sputum smear on diagnosis. Questions to measure the difficulties faced included financial hardship, fear of syringe injection, inconvenience in clinic visit trips, adverse reaction to prescribed drugs and psychological pressure. Patients were free to quote more than one problem. Questions to measure household economic conditions and medical expenses incurred included type of insurance and coverage, monthly self-pay amount on TB medications and adherence level of suggested community care schedule were reflected by questions on when these patients returned to work.

\subsection{Statistics Analysis}


Data analysis was conducted using Statistical Analysis System (SAS 9.2 version). Chi-square test was used to measure difference between high and low insurance coverage groups. $P$-values were reported to assess the statistical significance $(p<0.05)$ of the difference.

\section{Results}

\subsection{Demographic characteristic (Table 1)}

A total of 77 patients comprising 56 male and 21 females in the age group of 18-68 were interviewed in this study. Among them $70 \%$ were married. $70 \%$ were non-local patient. In terms of income, over $66 \%$ of them were from the no- and low-income group. Proportion of patients returning to work on hospital discharge were $48 \%$ and $9 \%$ in married and single persons $(p=0.001)$.

\subsection{Medical Care received (Table 2)}

$79 \%$ (61) of the patients were hospitalized after MDR-TB diagnosis with an average hospital stay of 14.45 days. $74 \%$ (57) of patients were sputum positive on diagnosis.

\subsection{Insurance Coverage (Table 3)}

In our study, $26.0 \%$ (20) of the patients were covered by NRCMS, $53.2 \%$ (41) covered by UEBMI \& URBMI, only $1.3 \%$ (1) covered by commercial insurance, $19.5 \%$ (15) had not bought any medical insurance for themselves. Proportion of patients went back to work were $23 \%$ with no insurance and/or NRCMS and $45 \%$ with UEBMI / URBMI and commercial insurance. Significant difference was shown between these two insurance coverage groups $\left(c^{2}=5.059, p=0.033\right)$.

\subsection{Difficulties faced during treatment (Figure2)}

During MDR-TB treatment, patients encountered a range of difficulties including financial pressure (43\%), psychological stress (34\%), adverse drug reactions (30\%), repulsiveness towards the use of syringe injections (23\%). Patients in this study were free to choose more than one difficulty.

\subsection{Financial burden (Figure 3)}

On average, $48.1 \%$ (37) of the patients spent over USD300 per month on treatment. $28.6 \%$ (22) patients incurred costs of between USD150-300 per month. $23.4 \%$ (18) patients spent an additional of less than 
USD150 per month.

\section{Discussion}

Multidrug-resistant tuberculosis (MDR-TB) poses a huge challenge to public health system in terms of treatment costs and disease control[8]. In 2012, the China government laid out a program for the treatment and care of MDR-TB, suggesting hospitalization and community care (home isolation) for patient management. It recommended patients to be hospitalized for about 2 months, followed by community care until treatment completion[9]. However, this was constrained by the variance of medical resources, infrastructure and their availability in different areas of China. Home isolation schedule adherence is also poor due to catastrophic cost associated with the disease[10]. We conducted a survey with enrollment from 3 mid- to high-income cities of China to review and identify potential factors and their impacts on city patients. Suggestions on improving and enhancing future policy design were then made based on the findings.

Beijing is the capital of China. Shenzhen is a special administrative region and enjoys a prime geographic location. Jiangmen is part of the Guangdong province and is benefitting from its fast development. These 3 cities are characterized by a relatively high GDP with a correspondingly high cost of living.

\subsection{Risk of transmission from home-discharged "mid-income" patients}

It has been reported that effective treatment of MDR-TB patients can quickly reduce its contagiousness[11, 12]. Some studies focusing on treatment outcome also claimed ambulatory-based MDR-TB management is more cost effective than hospital-based schemes[13-15]. Theoretically three weeks of effective treatment is enough to have the infectiousness of MDR-TB significantly controlled[11, $16]$.

However, treating MDR-TB is far more complicated. It has been reported that pooled treatment success was about $60 \%$ in MDR-TB patients $[17,18]$. In the absence of new drugs such as bedaquiline, delamanid and linezolid, the success treatment outcome of MDR-TB with standardized second-line regimen in China before 2018 was only about $50 \%[19,20]$. We doubted that part of the MDR-TB patient with treatment failure were turned into XDR-TB in the end and undermined a large part of the efforts made in disease control. It has been reported that high rates of transmission from patients to exposed persons occurred when treatment regimens were 'ineffective'[11]. Dheda, et al. reported that highly drug-resistant strains were spreading in the community from home-discharged patients and generating secondary cases with poor treatment outcomes[21].

Recent studies from China using genomic epidemiological approach have shown that new infection was the main cause of MDR-TB, and smear-negative tuberculosis patients are also part of the source of 
transmission[22-25]. It is unclear how many of the patients still on treatment regimen were contributing to the spread of the disease.

Therefore, the risk of transmission is a challenge that needs to be addressed immediately. Our study showed that about $80 \%$ (61) MDR-TB patients were hospitalized and $74 \%$ (57) of them were smear positive at the time of admission. Average hospital stay for these patients were 2 weeks, which is below the suggested length of inpatient care. $36.4 \%$ (28) patients returned to work and participated in social activities immediately afterwards. This is especially true for those who were married and were the bread earner. Findings in our study showed a substantial difference in the ratio between the married (48\%) and singles (9\%) in returning to work during the suggested home isolation period. "If I do not go to work, the family has not enough income, and I might be out of job and cannot pay the premium on my own. Without insurance coverage, I have to absorb all costs of medical treatment. This is the vicious outcome my family and I cannot afford."A MDR-TB patient who worked as a taxi driver told us. This behavior, however, posed an alarming transmission threat to the community. Performance-linked incentives can be provided from care provider's level down to include patients to promote treatment adherence on a twosided monitoring basis.

\subsection{Financial hardship and catastrophic cost}

The costs for treating MDR-TB were reported to range from US\$1,218 to US\$83,365 per case[8, 26]. This includes treatment cost, and other indirect costs such as transport cost and income loss. Potential loss of insurance coverage as a result of job lost could further aggravated these patients' financial burden. Despite constant efforts the China Government made in health care measures trying to ease financial difficulties, but many kinds of medicine are not provided free of charge, especially new effective medicines such as linezolid and cycloserine. Many MDR-TB patients reflected that one of the major problems from the illness was still financial hardship[27-29]

Many studies have proved total cost spent on treating MDR-TB to be catastrophic for patients from most low- and middle-income families[30, 31].Surprisingly we found the middle working class were struck the hardest financially. Their relatively high cost of living, with an expensive-to-treat disease left them with a drained disposable household income. Their urge to return to work despite treatment status was the most alarming among all income groups.

Our study showed a direct relationship between the proportion of patients failing community care and the increase in foreseeable self-borne medical expenses. From the perspective of insurance coverage, $100 \%$ of patients obtaining self-paid commercial insurance and $46 \%$ of patients under UEBMI / URBMI returned to work before they were supposed to do so. Under UEBMI, employer has to pay $75 \%$ of premium for the employee. If one is out of job, they would have to bear full premium in keeping the insurance. Only $20 \%$ of patients without insurance coverage returned to work on hospital discharge, which is lower than the group covered by NRCMS (25\%). 
The same observation was reflected by out-of-pocket expenses. When monthly expenditure went above USD150, over $39 \%$ of patients chose to return to work despite the suggested home isolation care. This is true for patients under all kinds of insurance except NRCMS. The reason behind this could be the cost of keeping the insurance coverage. Premium for NRCMS is only USD4.5 / year which is way below any other insurance premium included in this study.

In combating this problem, the government could consider full medical coverage for MDR-TB patients, through special TB protection and registration programs, to enable expenses to be credited directly to the government, or an appointed agent. This can simplify the application and reimbursement process made on a per visit basis, and sooth patient's fundamental financial difficulty.

\subsection{Problems faced during treatment and possible solutions}

Although WHO had downregulated the importance of second-line injections in 2018, it was still widely used in many MDR-TB regimens in China in 2017[32,33]. When new drugs are unavailable, clinicians will resort to injection to construct part of an effective regimen. The pain and uncomfortable experience with injection discouraged most patients from adhering to treatment. And deficient regimen and insufficient treatment are among the main causes which led to more drug resistance and treatment failure[34, 35].

Furthermore, most anti-MDR-TB drugs have obvious toxic side effects which cause treatment adherence failure. A 62-year-old female MDR-TB patient in our study has stopped treatment on her own several times. Her current drug sensitivity test turned out to be XDR-TB.

In addition, most MDR-TB patients suffer from severe psychological stress[36, 37]. Worrisome thoughts included their illness being difficult to cure and the fear of spreading the disease to their family and friends. At the same time, they also worried about being isolated and alienated by their friends and family.

Providing care providers with free TB drugs and patients with new and effective oral medications, counselling service, and organizing patient groups to share experience will help them get the emotional support they need to complete treatment. This in turn would reduce disease spreading and minimize drug-resistance TB to be further developed.

There were some limitations in our study. Firstly, the participants were only from 3 cities therefore are not representative of all MDR-TB patients. The lack of control groups hindered comparisons with other population groups. Secondly, some patients refused to be interviewed or lost contact, which may have contributed to a loss of important relevant information and caused selection bias leading to underestimation of the difficulties the overall MDR-TB patients are facing. Thirdly, the study had not measured the risk of disease transmission from these patients who were currently on TB treatment, 
therefore no conclusions can be drawn on the relationship between airborne risk and infection risk spread by the said patients in the current study.

In summary, poverty and TB control has long been proved to have an inverse correlation. Tackling the problem must start from the root cause to alleviate caseload, all the way up to follow-up management of patients to minimize transmission and disease progression. Funding, free effective new oral medicine, providing patient-centred support and performance-linked incentives together could make a major step towards treatment success for TB.

\section{Abbreviations}

MDR-TB: Multidrug-resistant tuberculosis

XDR-TB: Extensively drug-resistant tuberculosis

TB: Tuberculosis

NRCMS: The New Rural Co-operative Medical Care Scheme

UEBMI: Urban Employee Basic Medical Insurance

URBMI: Urban Residents Basic Medical Scheme

CNY: Chinese Currency

USD: United States Dollars

\section{Declarations}

\section{Acknowledgement}

The authors are grateful for the continued academic support from The National Clinical Research Center for Infectious Disease in China and China Tuberculosis Clinical Trial Consortium (CTCTC).

\section{Source of funding}

This study was funded by the 13th Five-Year Major Science and Technology Project of China(2018ZX10715004-002-007) which is a government fund for the research of tuberculosis treatment and control. 


\section{Authors' contributions}

Peize Zhang: Project coordination, training of data collectors, data analysis, manuscript preparation and drafting. Guanghui Xu, Yanhua Song, Jie Tan, Tao Chen: face-to-face and phone-call interview, manuscript review. Peize Zhang, Guofang Deng: Conception and design of work, manuscript review. All listed authors have read and approved this manuscript.

\section{Availability of data and materials}

The data sets used and / or analyzed in this study are available from the corresponding author on reasonable request.

\section{Ethics approval and consent to participate}

Ethical approval for the study was granted by the Research Ethics Committee at the 13th Five-Year Major Science and Technology Project of China. Participants were informed in the local language explaining the study purpose and design, confidentiality, risks and benefits and freedom to refuse. All participants provided dated signature in face-to-face interview or verbal consent in the phone call interview.

\section{Consent for publication}

No individual or identifiable persons' details are included in this manuscript.

\section{Competing interest}

The authors declare no competing interest.

\section{References}

1. WHO: Global tuberculosis report 2019. 2019. 
2. Haileamlak A: Infectious Diseases Continued to be the World's Core Challenge. Ethiop J Health Sci 2017, 27(6):570.

3. Meng Q, Xu K: Progress and challenges of the rural cooperative medical scheme in China. Bull World Health Organ 2014, 92(6):447-451.

4. Pan XF, Xu J, Meng Q: Integrating social health insurance systems in China. Lancet 2016, 387(10025):1274-1275.

5. Meng Q, Fang H, Liu X, Yuan B, Xu J: Consolidating the social health insurance schemes in China: towards an equitable and efficient health system. Lancet 2015, 386(10002):1484-1492.

6. Li C, Hou Y, Sun M, Lu J, Wang Y, Li X, Chang F, Hao M: An evaluation of China's new rural cooperative medical system: achievements and inadequacies from policy goals. BMC Public Health 2015, 15:1079.

7. Yuan B, Jian W, He L, Wang B, Balabanova D: The role of health system governance in strengthening the rural health insurance system in China. Int J Equity Health 2017, 16(1):44.

8. Tanimura T, Jaramillo E, Weil D, Raviglione M, Lonnroth K: Financial burden for tuberculosis patients in low- and middle-income countries: a systematic review. Eur Respir J 2014, 43(6):1763-1775.

9. Wang Y: Naiduoyao Feijiehe Fangzhi Guangli Fangan (in Chinese).

10. Tang S: Tackling challenges of TB/MDRTB in China: concerted actions are imperative. Infect Dis Poverty 2015, 4:19.

11. Dharmadhikari AS, Mphahlele M, Venter K, Stoltz A, Mathebula R, Masotla T, van der Walt M, Pagano $\mathrm{M}$, Jensen $\mathrm{P}$, Nardell E: Rapid impact of effective treatment on transmission of multidrug-resistant tuberculosis. Int J Tuberc Lung Dis 2014, 18(9):1019-1025.

12. Dheda K, Gumbo T, Maartens G, Dooley KE, McNerney R, Murray M, Furin J, Nardell EA, London L, Lessem $\mathrm{E}$ et al: The epidemiology, pathogenesis, transmission, diagnosis, and management of multidrug-resistant, extensively drug-resistant, and incurable tuberculosis. Lancet Respir Med 2017.

13. Bassili A, Fitzpatrick C, Qadeer E, Fatima R, Floyd K, Jaramillo E: A systematic review of the effectiveness of hospital- and ambulatory-based management of multidrug-resistant tuberculosis. Am J Trop Med Hyg 2013, 89(2):271-280.

14. Williams AO, Makinde OA, Ojo M: Community-based management versus traditional hospitalization in treatment of drug-resistant tuberculosis: a systematic review and meta-analysis. Glob Health Res Policy 2016, 1:10.

15. Taneja N, Chellaiyan VG, Daral S, Adhikary M, Das TK: Home Based Care as an Approach to Improve the Efficiency of treatment for MDR Tuberculosis: A Quasi-Experimental Pilot Study. J Clin Diagn Res 2017, 11(8):LC05-LC08.

16. Farmer PE, Raviglione MC: Rapid impact of effective chemotherapy on transmission of drugresistant tuberculosis: pity the guinea pig. Int J Tuberc Lung Dis 2014, 18(9):1009-1011.

17. Bastos ML, Lan Z, Menzies D: An updated systematic review and meta-analysis for treatment of multidrug-resistant tuberculosis. Eur Respir J 2017, 49(3). 
18. Collaborative Group for the Meta-Analysis of Individual Patient Data in MDRTBt, Ahmad N, Ahuja SD, Akkerman OW, Alffenaar JC, Anderson LF, Baghaei P, Bang D, Barry PM, Bastos ML et al: Treatment correlates of successful outcomes in pulmonary multidrug-resistant tuberculosis: an individual patient data meta-analysis. Lancet 2018, 392(10150):821-834.

19. Xu C, Pang Y, Li R, Ruan Y, Wang L, Chen M, Zhang H: Clinical outcome of multidrug-resistant tuberculosis patients receiving standardized second-line treatment regimen in China. J Infect 2018, 76(4):348-353.

20. Alene KA, Yi H, Viney K, McBryde ES, Yang K, Bai L, Gray DJ, Clements ACA, Xu Z: Treatment outcomes of patients with multidrug-resistant and extensively drug resistant tuberculosis in Hunan Province, China. BMC Infect Dis 2017, 17(1):573.

21. Dheda K, Limberis JD, Pietersen E, Phelan J, Esmail A, Lesosky M, Fennelly KP, te Riele J, Mastrapa B, Streicher EM et al: Outcomes, infectiousness, and transmission dynamics of patients with extensively drug-resistant tuberculosis and home-discharged patients with programmatically incurable tuberculosis: a prospective cohort study. The Lancet Respiratory Medicine 2017, 5(4):269281.

22. Yang C, Shen X, Peng Y, Lan R, Zhao Y, Long B, Luo T, Sun G, Li X, Qiao K et al: Transmission of Mycobacterium tuberculosis in China: a population-based molecular epidemiologic study. Clin Infect Dis 2015, 61(2):219-227.

23. Yang C, Luo T, Shen X, Wu J, Gan M, Xu P, Wu Z, Lin S, Tian J, Liu Q et al: Transmission of multidrugresistant Mycobacterium tuberculosis in Shanghai, China: a retrospective observational study using whole-genome sequencing and epidemiological investigation. Lancet Infect Dis 2017, 17(3):275-284.

24. Yang C, Lu L, Warren JL, Wu J, Jiang Q, Zuo T, Gan M, Liu M, Liu Q, DeRiemer K et al: Internal migration and transmission dynamics of tuberculosis in Shanghai, China: an epidemiological, spatial, genomic analysis. Lancet Infect Dis 2018, 18(7):788-795.

25. Yang C, Gao Q: Recent transmission of Mycobacterium tuberculosis in China: the implication of molecular epidemiology for tuberculosis control. Front Med 2018, 12(1):76-83.

26. Diel R, Vandeputte J, de Vries G, Stillo J, Wanlin M, Nienhaus A: Costs of tuberculosis disease in the European Union: a systematic analysis and cost calculation. Eur Respir J 2014, 43(2):554-565.

27. Long Q, Smith H, Zhang T, Tang S, Garner P: Patient medical costs for tuberculosis treatment and impact on adherence in China: a systematic review. BMC Public Health 2011, 11:393.

28. Hutchison C, Khan MS, Yoong J, Lin X, Coker RJ: Financial barriers and coping strategies: a qualitative study of accessing multidrug-resistant tuberculosis and tuberculosis care in Yunnan, China. BMC Public Health 2017, 17(1):221.

29. Long Q, Qu Y, Lucas H: Drug-resistant tuberculosis control in China: progress and challenges. Infect Dis Poverty 2016, 5:9.

30. Zhou C, Long Q, Chen J, Xiang L, Li Q, Tang S, Huang F, Sun Q, Lucas H: Factors that determine catastrophic expenditure for tuberculosis care: a patient survey in China. Infect Dis Poverty 2016, 5:6. 
31. Chen S, Zhang H, Pan Y, Long Q, Xiang L, Yao L, Lucas H: Are free anti-tuberculosis drugs enough? An empirical study from three cities in China. Infect Dis Poverty 2015, 4:47.

32. China A-tao: Guideline of Chemotherapy for multi-drug resistance tuburculosis (2015). Zhongguo Fang Lao Za Zhi 2015, 37(5):421-469.

33. WHO: WHO treatment guidelines for drug-resistant tuberculosis (2016 update). 2016.

34. Wu S, Zhang Y, Sun F, Chen M, Zhou L, Wang N, Zhan S: Adverse Events Associated With the Treatment of Multidrug-Resistant Tuberculosis: A Systematic Review and Meta-analysis. Am J Ther 2016, 23(2):e521-530.

35. Javaid A, Ullah I, Masud H, Basit A, Ahmad W, Butt ZA, Qasim M: Predictors of poor treatment outcomes in multidrug-resistant tuberculosis patients: a retrospective cohort study. Clin Microbiol Infect 2018, 24(6):612-617.

36. Morris MD, Quezada L, Bhat P, Moser K, Smith J, Perez H, Laniado-Laborin R, Estrada-Guzman J, Rodwell TC: Social, economic, and psychological impacts of MDR-TB treatment in Tijuana, Mexico: a patient's perspective. Int J Tuberc Lung Dis 2013, 17(7):954-960.

37. Xu M, Markstrom U, Lyu J, Xu L: Survey on Tuberculosis Patients in Rural Areas in China: Tracing the Role of Stigma in Psychological Distress. Int J Environ Res Public Health 2017, 14(10).

\section{Tables}

Table 1. Demographic characteristics of patients participated in this study 


\begin{tabular}{|c|c|c|c|c|c|}
\hline haracteristics & $\begin{array}{l}\text { No. of } \\
\text { patients }\end{array}$ & $\begin{array}{l}\text { Proportion of total } \\
\text { no. of patients (\%) }\end{array}$ & $\begin{array}{c}\text { No. of patients } \\
\text { failed community } \\
\text { care }\end{array}$ & $\begin{array}{l}\text { Proportion of } \\
\text { the group (\%) }\end{array}$ & $\begin{array}{c}p- \\
\text { value }\end{array}$ \\
\hline \multicolumn{6}{|l|}{ iender } \\
\hline Male & 56 & $73 \%$ & 18 & $32 \%$ & \multirow[t]{2}{*}{0.200} \\
\hline Female & 21 & $27 \%$ & 10 & $48 \%$ & \\
\hline & & & & & \multirow{5}{*}{0.090} \\
\hline $18-35$ & 29 & $38 \%$ & 6 & $21 \%$ & \\
\hline $36-50$ & 21 & $27 \%$ & 10 & $48 \%$ & \\
\hline$>51$ & 27 & $35 \%$ & 12 & $44 \%$ & \\
\hline Iarital status & & & & & \\
\hline $\begin{array}{l}\text { Single / Divorced } \\
\text { Widowed }\end{array}$ & 23 & $27 \%$ & 2 & $9 \%$ & \multirow[t]{2}{*}{0.001 • } \\
\hline $\begin{array}{l}\text { Married } \\
\text { esidency }\end{array}$ & 54 & $70 \%$ & 26 & $48 \%$ & \\
\hline Local & 23 & $30 \%$ & 10 & $43 \%$ & \multirow[t]{3}{*}{0.400} \\
\hline Non-local & 54 & $70 \%$ & 18 & $33 \%$ & \\
\hline Iccupation & & & & & \\
\hline Student & 8 & $10 \%$ & 0 & $0 \%$ & \multirow[t]{4}{*}{0.090} \\
\hline Worker / Farmer & 23 & $30 \%$ & 6 & $26 \%$ & \\
\hline $\begin{array}{l}\text { White Collar / } \\
\text { fficer / Specialist }\end{array}$ & 18 & $23 \%$ & 10 & $56 \%$ & \\
\hline $\begin{array}{l}\text { Others (temp jobs } \\
\text { part-time } \\
\text { jobs / } \\
\text { nemployed } \\
\text { ducation level }\end{array}$ & 28 & $36 \%$ & 12 & $43 \%$ & \\
\hline Primary & 9 & $12 \%$ & 4 & $44 \%$ & \multirow[t]{4}{*}{0.500} \\
\hline $\begin{array}{l}\text { Junior high } \\
\text { ¿hool }\end{array}$ & 25 & $32 \%$ & 10 & $40 \%$ & \\
\hline $\begin{array}{l}\text { Senior high } \\
\text { shool }\end{array}$ & 24 & $31 \%$ & 10 & $42 \%$ & \\
\hline $\begin{array}{l}\text { College* } \\
\text { all students are in } \\
\text { iis group }\end{array}$ & 19 & $25 \%$ & 4 & $21 \%$ & \\
\hline $\begin{array}{l}\text { significant } \\
\text { ifference } \\
\text { bserved }\end{array}$ & & & & & \\
\hline
\end{tabular}

Table 2. Medical care for patients participated in this study 


\begin{tabular}{|c|c|c|c|c|c|}
\hline haracters & $\begin{array}{l}\text { Total } \\
(\mathrm{n}=77)\end{array}$ & $\begin{array}{l}\text { Proportion of } \\
\text { total (\%) }\end{array}$ & $\begin{array}{l}\text { Patients failed } \\
\text { community care }\end{array}$ & $\begin{array}{l}\text { Proportion of the } \\
\text { group (\%) }\end{array}$ & $\begin{array}{c}p- \\
\text { value }\end{array}$ \\
\hline putum smear & & & & & \\
\hline & 20 & $26.0 \%$ & 7 & $35.0 \%$ & 0.9 \\
\hline+ & 31 & $40.3 \%$ & 11 & $35.5 \%$ & \\
\hline & 10 & $9.1 \%$ & 3 & $42.9 \%$ & \\
\hline $\begin{array}{l}+++ \\
\text { [ospitalized }\end{array}$ & 19 & $24.7 \%$ & 7 & $36.8 \%$ & \\
\hline Yes & 61 & $79.2 \%$ & 20 & $32.8 \%$ & 0.2 \\
\hline & 16 & $20.8 \%$ & 8 & $50.0 \%$ & \\
\hline $\begin{array}{l}\text { verage hospitalized } \\
\text { eriod (Days) }\end{array}$ & 14.45 & & & & \\
\hline
\end{tabular}

Table 3. Insurance coverage of patients participated in this study

\section{INSURANCE COVERAGE}

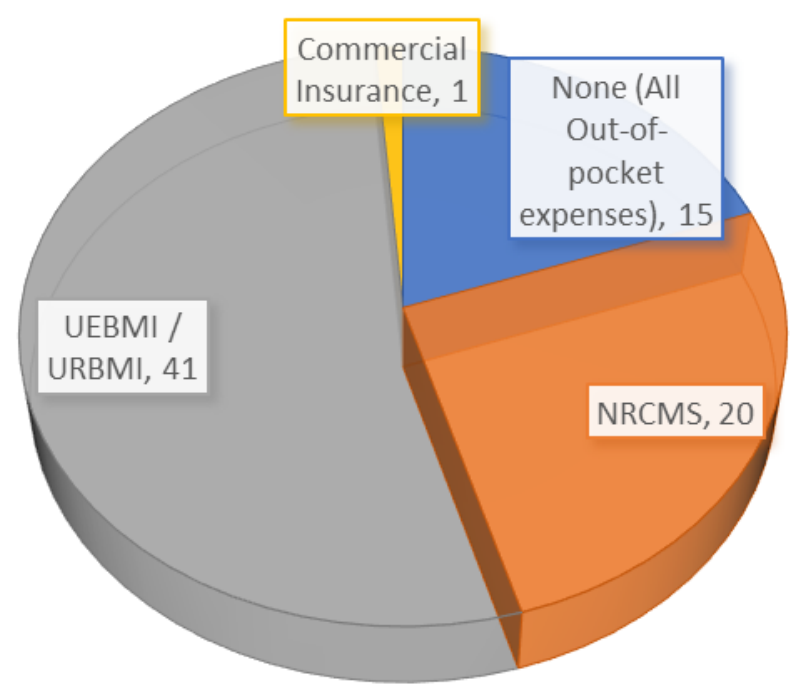

\begin{tabular}{|c|c|c|c|c|c|}
\hline \multirow[t]{2}{*}{ Type of Insurance } & \multicolumn{2}{|c|}{$\begin{array}{c}\text { Patients } \\
\text { interviewed }\end{array}$} & \multicolumn{2}{|c|}{$\begin{array}{l}\text { Patients failed community } \\
\text { care }\end{array}$} & \multirow[t]{2}{*}{ Statistics } \\
\hline & $\begin{array}{l}\text { No. of } \\
\text { ppl }\end{array}$ & $\%$ & No. of ppl & $\%$ & \\
\hline $\begin{array}{l}\text { None (All Out-of-pocket } \\
\text { expenses) } \\
\text { NRCMS }\end{array}$ & $\begin{array}{l}15 \\
20\end{array}$ & $45.45 \%$ & 8 & $22.86 \%$ & \multirow{2}{*}{$\begin{array}{c}c^{2}= \\
5.059 \\
p= \\
0.033\end{array}$} \\
\hline $\begin{array}{l}\text { UEBMI / URBMI } \\
\text { Commercial Insurance }\end{array}$ & $\begin{array}{r}41 \\
1\end{array}$ & $54.55 \%$ & 20 & $47.62 \%$ & \\
\hline \multicolumn{5}{|l|}{ 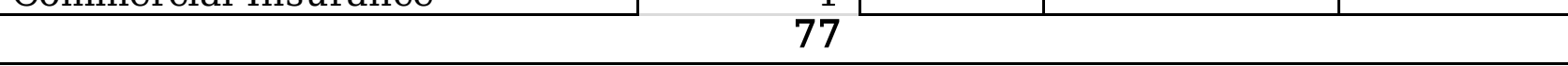 } & \\
\hline \multicolumn{5}{|c|}{$\begin{array}{l}\text { Abbreviations: } \\
\text { NRCMS - New Rural Co-operative Medical Scheme } \\
\text { UEBMI - Urban Employee Basic Medical Insurance } \\
\text { URBMI - Urban Residents Basic Medical Insurance }\end{array}$} & \\
\hline
\end{tabular}




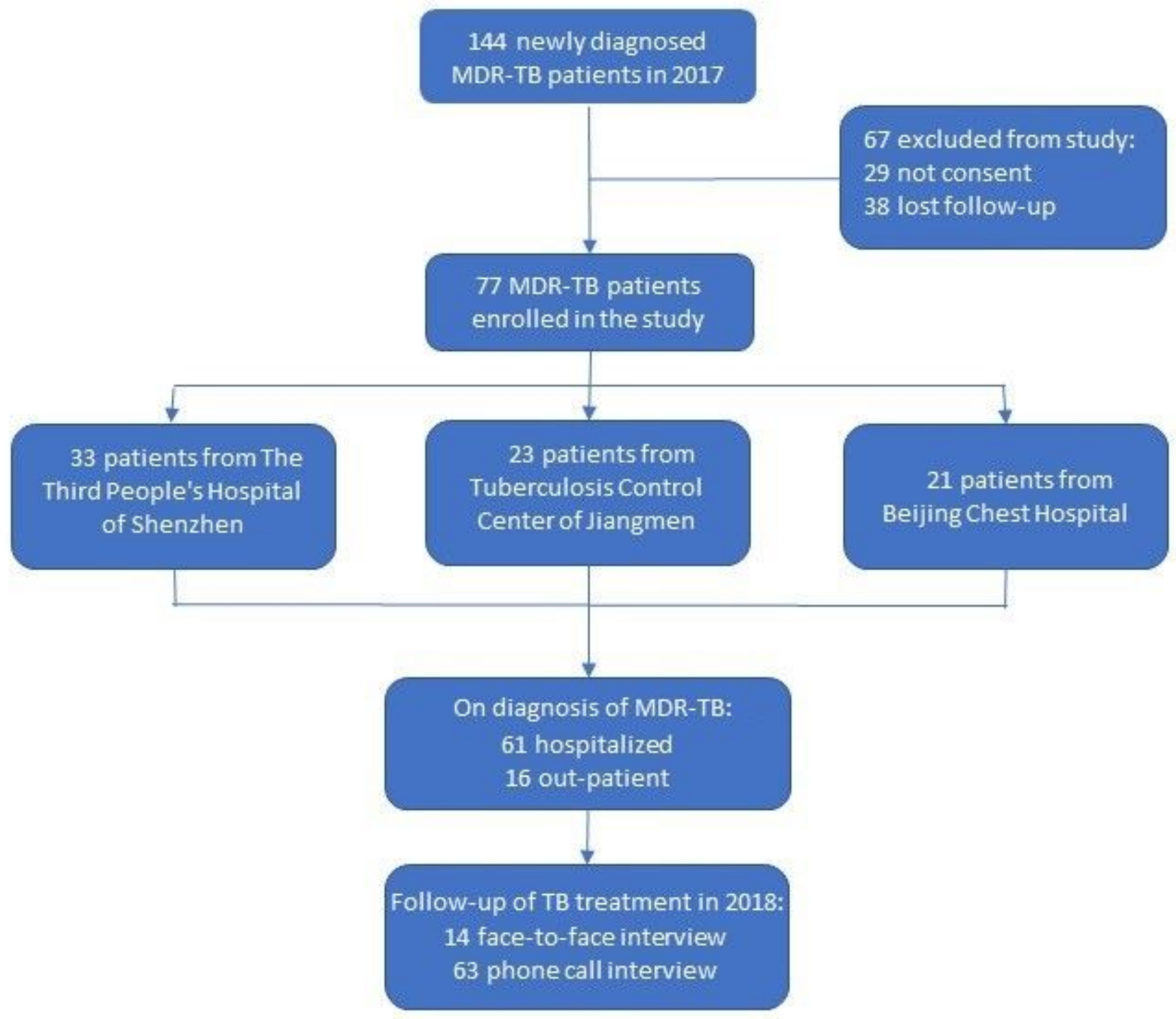

\section{Figure 1}

Flowchart of case recruitment in this study 


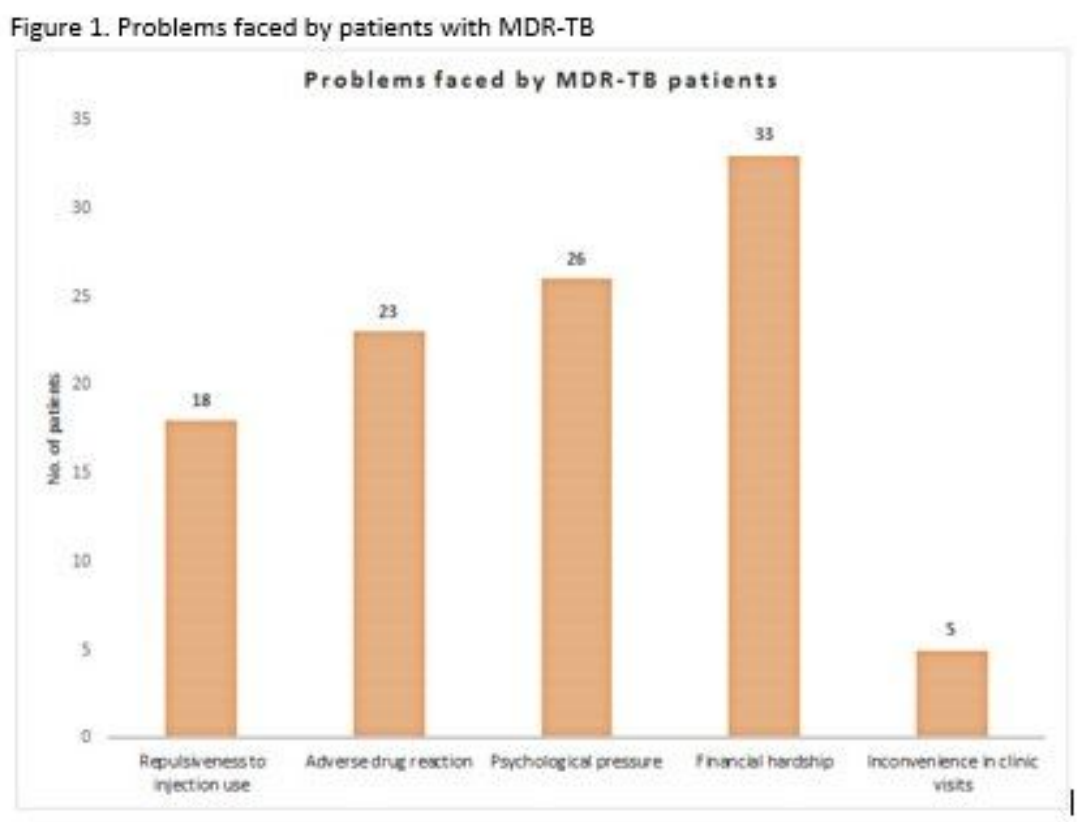

Figure 2

Problems faced by patients with MDR-TB

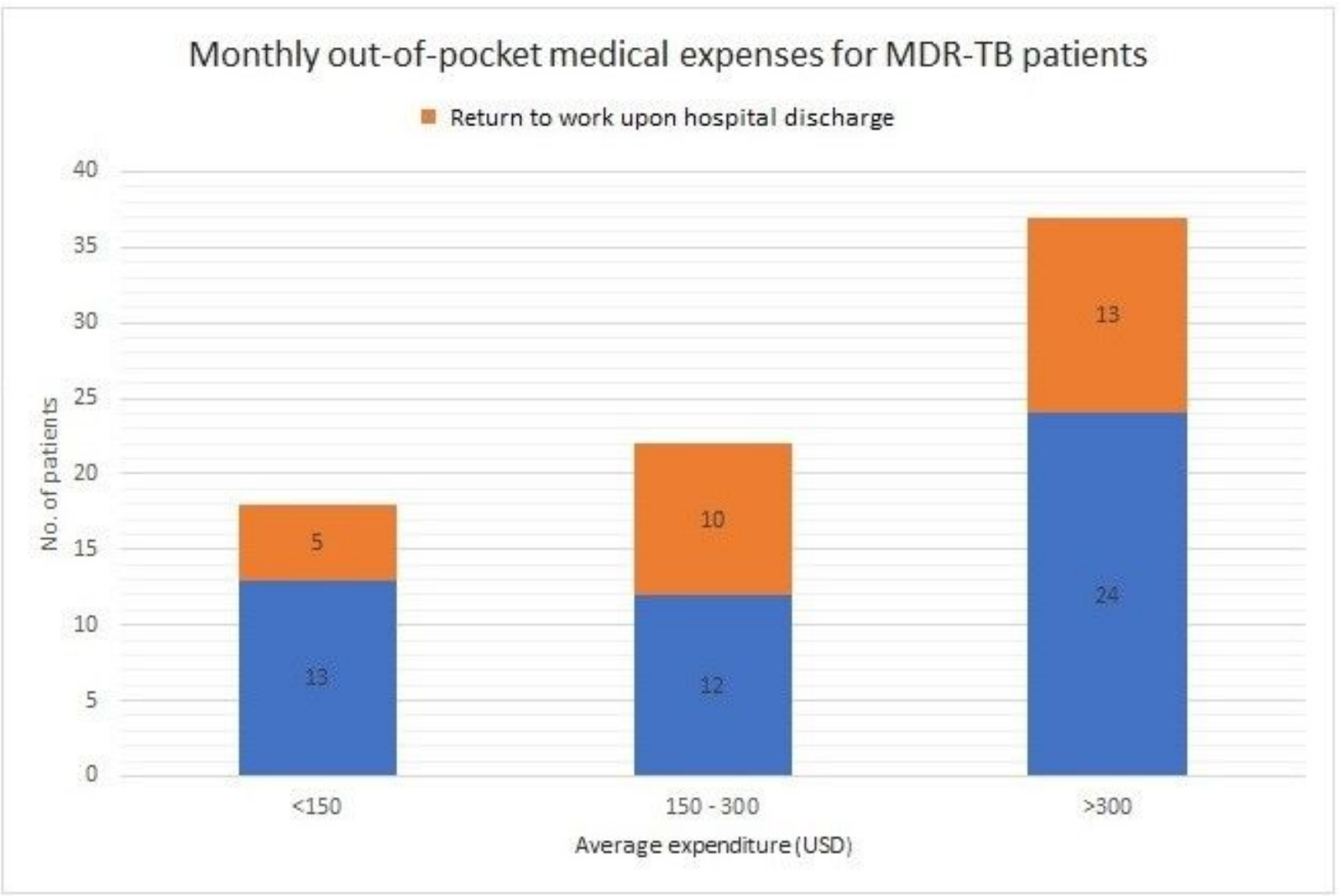

Figure 3 
Monthly out-of-pocket medical cost for patients with MDR-TB 